\title{
MEMÓRIA E INSTITUIÇÃO: A FACULDADE DE DIREITO DA UFPR ENTRE 2008 E 2016*
}

\author{
Ricardo Marcelo Fonseca ${ }^{* *}$
}

Magnífico Reitor da Universidade Federal do Paraná, prof. dr. Zaki Akel Sobrinho;

Excelentíssimo Vice-Reitor da Universidade Federal do Paraná, prof. dr. Rogério Andrade Mulinari;

Excelentíssima Diretora da Faculdade de Direito da UFPR, prof. ${ }^{a}$ dr. $^{\text {a }}$ Vera Karam de Chueiri;

Excelentíssima Vice-Diretora da Faculdade de Direito da UFPR, prof. ${ }^{a}$ dr. ${ }^{a}$ Maria Cândida Kroetz;

Caríssimo Secretário do Centro Acadêmico Hugo Simas, acadêmico Rodrigo Saturnino;

Prezadíssimos pró-reitores, diretores e vice-diretores de setor, autoridades acadêmicas e institucionais, colegas professores, servidores técnico-administrativos, estudantes, senhoras e senhores.

Hoje eu vivo um momento de grande e indefinida emoção. Um sabor agridoce de ter, de um lado, que deixar esse lugar, a Direção da Faculdade de Direito, onde tanto me envolvi, à qual tanto me dediquei, um lugar de tantas pessoas queridas com quem convivi. Um lugar, definitivamente, que vivi, e vivi intensamente. Mas ao mesmo tempo, de outro lado, esse momento encerra um ciclo, é renovação e abre para o novo - e o tempo da renovação também é parte importante da vida.

Que me seja permitido então tomar a ajuda da ideia do tempo para lidar com essas emoções indefinidas. O tempo, que já guiou meu discurso de posse, aqui nesse Salão Nobre, há cerca de oito anos. Que me seja permitida a repetição, pois sou historiador do direito e o recurso às memórias e às astúcias da temporalidade é para mim vício do meu ofício. Faz parte do meu modo de ver o mundo nos colocarmos nessa moldura complexa que é o tempo.

O tempo e a memória são adequados para refletir sobre esse momento e esse espaço, que é vetusto, tradicional, fundador da nossa UFPR, mas também é espaço de renovação, de transformação,

\footnotetext{
${ }^{*}$ Discurso de entrega do cargo como Diretor da Faculdade de Direito da UFPR, em cerimônia ocorrida no dia $1^{\circ}$ de agosto de 2016, no Salão Nobre do Prédio Histórico da UFPR.

** Professor do Setor de Ciências Jurídicas da UFPR (Curitiba, PR, Brasil).
} 
de vida nova. O tempo diz muito sobre essa comunidade - que se orgulha do seu lugar e do seu tempo - e diz muito sobre esse exato momento em que vivo agora, ao deixar esse lugar que ocupei por esse longo período.

E se a “memória é a faculdade épica por excelência”, como diz Walter Benjamin", peço a licença de puxar o fio da memória pessoal na minha relação com esse espaço e buscar entrelaçá-lo com a minha memória institucional para, com isso, tentar fazer os registros de gratidão e a prestação de contas da gestão que me proponho a fazer nesse meu discurso.

Não vou mentir: quando criança, olhando de fora, achava esse Prédio Histórico monumental e impressionante; mas quando conheci esse espaço por dentro, ele me pareceu opressivo: hostil com quem vinha de fora, com um orgulho talvez excessivamente elitista de sua tradição, com algumas feições demasiado altivas. Nos meus primeiros tempos aqui eu me concentrei nas feições amigas, nos alunos maravilhosos que aqui sempre encontrei e fui buscando, sem pressa, tijolo por tijolo, o meu lugar e o meu espaço. Fui lentamente formando laços, criando amizades e ganhando a confiança de colegas e mestres. Luiz Fernando Coelho foi o que primeiro me estendeu sua mão; depois dele, sempre e até hoje, Celso Ludwig; a seguir, Joaquim Munhoz de Mello, Alcides Munhoz da Cunha, José Antonio Peres Gediel, Luiz Edson Fachin, nos passos que dei no mestrado, no doutorado e ao ingressar aqui como professor e depois ao ser credenciado no programa de pós-graduação.

Mas ocupar um lugar político aqui sempre foi algo mais complicado. Como um exemplo emblemático do que quero dizer, puxo o fio da lembrança do ano de 2001, quando ocorreu um episódio emblemático. Pelas mãos de Fachin e Gediel, eu ocupei a vice-coordenação do curso de graduação em direito, para secundar a saudosa professora Carmem Lucia Silveira Ramos. Naquele ano, o MEC viria fazer uma avaliação do nosso curso. Num tempo em que não havia currículos Lattes e nem sistemas on line, fui incumbido de levantar os dados da produção dos professores para nos prepararmos para essa visita. Para isso, enviei ofícios a todos os docentes, o que para mim era uma ação comezinha e simples, mas que despertou fagulhas no complexo espaço que sempre foi essa Faculdade de Direito. Numa reunião setorial ocorrida logo em seguida, o diretor Fachin foi confrontado por alguns professores, por eles estarem recebendo ofícios de um zé-ninguém. Um dos docentes - já não mais entre nós - lançou a seguinte frase, que para mim é tão emblemática: "Fachin, a Faculdade é composta de cardeais; e cardeais querem receber ofícios do papa, e não do porteiro do prédio”.

Eu rememorei esse episódio uma única vez antes, justamente num debate da campanha

\footnotetext{
${ }^{1}$ BENJAMIN, Walter. Obras escolhidas - magia e técnica, arte e política: ensaios sobre literatura e história da cultura. 8. ed. São Paulo: Brasiliense, 2012. p. 227.
} 
eleitoral para a Direção desta Faculdade, em 2008. Naquela ocasião, disse aos estudantes: “Vamos acabar com a era dos cardeais nesse curso de Direito! Vamos eleger pela primeira vez um porteiro do prédio como Diretor da Faculdade de Direito da UFPR!” E assim aconteceu.

Conto isso para dizer como o espaço era complexo e como o caminho foi duro. Como foi longa a trajetória para que esse lugar, de estranho e opressivo, tivesse se transformado em minha casa e no espaço onde mais depositei, até hoje, minha energia vital.

E em 2008, como dito, e contra os prognósticos de alguns, fui eleito, sempre com Vera ao lado, Diretor dessa vetusta Faculdade. E em 2012 - desta vez sem bate-chapa - fui reeleito para o mandato que termina justamente hoje.

Oito anos! Em oito anos acontece muita coisa! Na vida individual de uma pessoa, como eu, ou numa vida institucional, como nessa Faculdade. Nesses oito anos vi alguns de meus entes mais queridos irem; mas ao mesmo tempo vi meus filhos crescerem. Quando tomei posse, em meados de julho de 2008, nesse mesmo auditório, meu filho Antonio tinha recém saído da maternidade.

Mas eu puxo o fio da memória para falar dessa Faculdade e desses últimos oito anos, que a partir de agora vão compor a sua memória institucional. O já referido Walter Benjamin também disse, ao refletir sobre o Legado de Marcel Proust, que "um acontecimento vivido é finito, ou pelo menos encerrado na esfera do vivido, ao passo que um acontecimento rememorado é sem limites, pois é uma chave para tudo o que veio antes e depois"2.

Oito anos atrás, encontramos um curso conflagrado, marcado pelo conflito, e onde não havia reuniões de conselho setorial há um ano e meio; encontramos um clima de hostilidade entre professores e alunos e entre alunos e técnicos; encontramos feudos estabelecidos; encontramos dinâmicas administrativas paralelas que nem sequer chegavam ao conhecimento do Gabinete; encontramos a “Revista da Faculdade de Direito UFPR” com a classificação B5 no sistema Qualis; encontramos um currículo que já estava defasado desde 2004, quando foram editadas as novas diretrizes curriculares do curso de direito (pela Resolução 09/2004-CNE/MEC); encontramos um Núcleo de Prática Jurídica que tinha recentemente passado pela crise de ter que ver irem embora os “advogados contratados” pela Funpar, por exigência dos órgãos de controle, e que sobrevivia somente com professores substitutos; encontramos um Prédio Histórico sucateado e mal cuidado; encontramos um curso que virava as costas para a Universidade, recusando-se a interagir e dialogar; encontramos um curso carcomido por algumas velhas práticas e vícios, pela falta de solidariedade interna. E encontramos diante de nós o desafio da implementação da ampliação das vagas pela nossa adesão ao

\footnotetext{
2 BENJAMIN, Walter. Obras escolhidas - magia e técnica, arte e política: ensaios sobre literatura e história da cultura. 8. ed. São Paulo: Brasiliense, 2012. p. 38-39.
} 
Reuni.

Oito anos de desafios contínuos e cotidianos; oito anos de muito trabalho, em tempo integral; oito anos de reconstrução de laços e de solidariedades; oito anos de diálogo e de negociações e ocasionalmente de conflitos. E creio que há resultados obtidos, e deles agora eu presto contas a essa comunidade.

No ano de 2009 realizamos um processo amplo, aberto e democrático de discussão de nosso projeto pedagógico. Nunca houve, ao menos em minha memória, um momento em que o curso tenha se mobilizado tanto e tão profundamente, para discutir a si mesmo. A partir de um calendário de discussões debatido com a comunidade, cada departamento, o colegiado do curso e o conselho setorial realizou pelo menos quatro reuniões plenárias para debater o novo curso; reuniões das comissões com os departamentos e assembleias estudantis. Tudo isso desembocando num riquíssimo debate e em um novo curso de direito, que passou a vigorar a partir de 2010. Desde o ano de 2015, após atravessarmos a fase sempre intranquila de transição curricular, o novo projeto está inteiramente implementado. Com ele, o curso ficou mais denso e com maior carga horária; foram criadas novas disciplinas e outras saíram da matriz curricular; a carga horária de disciplinas foi redimensionada; foi criada uma terceira área de habilitação - a de "teoria do direito e direitos humanos" - buscando enriquecer a formação do graduando e efetivar uma homologia com o modo exitoso como funcionavam as áreas de concentração de nosso programa de pós-graduação; a área dos direitos humanos se transformou num eixo transversal na formação dos estudantes; o currículo foi parcialmente flexibilizado, dando um papel muito mais ativo ao estudante em seu processo formativo; ao mesmo tempo, com a criação das disciplinas tópicas e com o aumento da parte “flexível” da grade, os professores puderam compartilhar melhor com o âmbito da graduação a dimensão de excelência na pesquisa que se dava na pós-graduação - reafirmando a grande verdade de que uma pós-graduação de excelência pode e deve retroalimentar e incrementar o ensino de graduação; criamos os núcleos de pesquisa no âmbito da graduação; a pesquisa foi incrementada, divulgada nesse período, com um aumento significativo das esferas da graduação e pós-graduação; foram aumentadas e fomentadas as ações de iniciação científica e do PET; potencializamos as dimensões da pesquisa e da extensão na formação dos nossos estudantes, substituindo parcialmente a parte flexível do currículo por essas atividades, e inserindo a extensão como atividade possível do Trabalho de Conclusão de Curso; a extensão sofreu um processo de amadurecimento (para afastar-se de mero assistencialismo e conectar-se de modo orgânico com o currículo) e passou a ter um papel efetivo na formação dos nossos estudantes.

Nesse passo quero chamar atenção para a recriação de uma unidade nova, que se reestruturou a partir do chão: o nosso Núcleo de Prática Jurídica. Ele foi reestruturado sob outra concepção: é 
formado exclusivamente por professores titulados e qualificados, que aliam a técnica da formação profissional, o preparo acadêmico e a atividade extensionista socialmente comprometida. Hoje, embora tenha a estrutura de um órgão suplementar do Setor, tem o destino traçado para se transformar em um Departamento: já tem quase o número de professores necessário e já detém representação no Conselho Setorial e no Colegiado de Curso. É hoje uma unidade pujante, moderna, que orgulha o nosso curso de Direito e que deu um salto qualitativo no eixo profissional de formação de nossos alunos.

Hoje, com o currículo novo, a formação de nossos estudantes é mais completa; integrou-se de modo equilibrado e efetivo a esfera da formação profissional (que para nós é uma dimensão crucial), a esfera da formação intelectual e a esfera da formação para a cidadania. Os resultados dessa implementação curricular estão nos dados disponíveis a todos: no último teste da OAB que teve seus resultados planilhados (teste nacional, em que participam as cerca de 1.400 faculdades de Direito brasileiras), o curso de Direito da UFPR ficou em $2^{\circ}$ lugar. Os dados de crescimento da extensão são eloquentes e falam por si sós: em 2009 a extensão no nosso curso teve quatro bolsas de extensão concedidas, havia um programa de extensão, quatro projetos de extensão e cinco eventos de extensão; já em 2015 fechamos com 62 bolsas de extensão (aumento de 1.450\%), três programas de extensão (aumento de 200\%), 21 projetos de extensão (aumento de mais de 400\%) e 28 eventos de extensão (aumento de mais de 450\%).

Os dados da pesquisa parecem ainda mais relevantes: nosso programa de pós-graduação em direito se consolidou como o melhor programa da área no País na última avaliação trienal da Capes; não por acaso, o comitê da área considerou que ele deveria ser alçado à nota 7 - seria a primeira nota 7 de um programa em direito do Brasil, e o primeiro programa nota 7 da nossa UFPR; vicissitudes várias fizeram com que o CTC/Capes não chancelasse a decisão da área. Mas no mundo jurídico brasileiro todos sabem que aqui é o lugar da produção mais acadêmica, diversificada, rica e internacionalizada no âmbito jurídico. Não por acaso, nesse período, tivemos sete Escolas de Altos Estudos/Capes (um edital aprovado diretamente pela presidência da Capes, destinado somente à permanência de professores de alta qualificação internacional no Brasil por pelo menos um mês), sendo duas delas coordenadas pessoalmente por mim. Na área do direito no Brasil, poucos programas fizeram uma dessas iniciativas, e na UFPR, que seja do meu conhecimento, nenhum outro programa o fez. Tivemos professor convidado estrangeiro (inclusive lecionando para a graduação e orientando pesquisas). Esse setor, durante esse período, transformou-se no palco ininterrupto dos maiores nomes acadêmicos do Brasil e do mundo, em eventos isolados, seminários e congressos nacionais e internacionais. De uma lista longuíssima de infindáveis nomes, permitam-me lembrar que estiveram 
nesse mesmo auditório, nesse período, Agnes Heller, Paolo Grossi, António Hespanha, Natalino Irti, Massimo Pavarini, Muñoz Conde, Kai Ambos, Raffaele De Giorgi, Antonio Baylos, Pietro Costa, Carlos Petit, entre tantos, tantos outros. A nossa Revista - que, como dito, tinha a avaliação B5 no sistema Qualis em 2008 - hoje tem avaliação A2.

Os nossos espaços foram melhorados, sofrendo um salto qualitativo: desde as coisas mais comezinhas, tais como paredes pintadas e limpas, pisos polidos e encerados e elevadores não degradados (que eram coisas que antes não conhecíamos), passamos a ter também salas com equipamentos multimídia, microfones nas salas de aula grandes, splits para conforto térmico em quase todas as salas. Obtivemos algumas telas interativas e equipamentos para criar uma sala de videoconferência de graduação. Tivemos uma (um tanto traumática) reforma no telhado e uma melhoria imensa em espaços do terceiro andar (como na nossa "sala de defesas") e nos espaços do segundo andar.

Na reorganização de espaços que tínhamos, obtivemos uma sala de reuniões digna, uma sala dos professores espaçosa e - esse ponto a mim é muito caro - a criação de dois pequenos auditórios que estão, a meu ver, entre os mais belos de toda a Universidade: em 2012 a "Sala da Memória” (na Sala Prof. José Munhoz de Mello), que, entre os belos vitrais coloridos, é um verdadeiro tributo à memória desse prédio que é o símbolo da cidade de Curitiba; e em 2015 a "Sala Alcides Munhoz da Cunha” (ou Sala 200, que é justamente o nosso atual espaço de videoconferência para a graduação). Os três auditórios que temos, Magnífico Reitor, que são usados intensivamente por nós, mas também por toda a comunidade da UFPR, para a qual o nosso curso, nesses oito anos, se abriu.

E também obtivemos um aumento de espaços: após mais de 20 anos sem que tivéssemos ganho um palmo a mais, garantimos, no início de 2015, um aumento de aproximadamente 1.500 metros quadrados de área no terceiro andar (na ala da Rua XV de Novembro), que deu vazão para nossos projetos de extensão, PET, salas de aula da pós-graduação (que são usadas também nas disciplinas tópicas da graduação) e alguns gabinetes de professores.

Quando assumimos em 2008, tínhamos 53 professores efetivos, e alguns substitutos, sobretudo no NPJ; com a administração racional dos pontos que recebemos do Reuni e dos pontos equivalentes que tínhamos pelo critério histórico, e com o auxílio da administração central da Universidade entre 2009 e 2010 no que diz respeito aos códigos de vagas docentes, hoje temos 80 professores efetivos e seis substitutos.

Ainda mais: ao longo desse período de oito anos promovemos 29 mudanças de regimes de trabalho de nossos professores - seja do regime de 20 para 40 horas, seja de 40 para DE ou de 20 para $\mathrm{DE}$, de modo que hoje temos quase $70 \%$ do nosso contingente de professores em regime de trabalho 
de dedicação integral ou dedicação exclusiva, revelando também uma mudança sensível no perfil docente no período.

Tínhamos 25 técnicos e muitos feudos; hoje temos 30 técnicos comprometidos e dedicados. Houve aumento de cerca de $20 \%$ dos nossos alunos da graduação, e de $50 \%$ dos nossos alunos do mestrado e doutorado.

Mas buscamos também, nesse período, cultivar nossa boa tradição, cultuar nossa memória e respeitar nossos servidores egressos. Criamos uma Resolução que instituiu uma cerimônia aos professores jubilados, dando a necessária valorização institucional a quem aqui dedicou boa parte de sua vida. Como não lembrar, por exemplo, da cerimônia em que nos despedimos dos professores Nicz e Malachini? Investimos todos os esforços institucionais na comemoração do nosso centenário ao final do ano de 2012, juntamente com o centenário da UFPR. Fizemos um evento marcante, neste Salão Nobre, em que homenageamos ex-diretores, ex-catedráticos, os aposentados, os professores titulares e eméritos. Reunimos aqui, no dia 18 de dezembro de 2012, mais de cinquenta anos de história de nossa Faculdade de Direito e nos emocionamos com a presença dos nossos professores titulares e jubilados, bem como dos professores Egas Moniz de Aragão, Sansão José Loureiro, René Dotti, Aloísio Surgik, Luiz Fernando Coelho, Assis Gonçalves, Joaquim Munhoz de Mello, Alcides Munhoz da Cunha, Eduardo Leite, além dos familiares dos professores Fernando Andrade Oliveira e Luiz Alberto Machado - que não puderam comparecer pessoalmente na ocasião por razões de saúde.

Após nossa iniciativa e aprovação do Conselho Universitário, concedemos o título de Professor Emérito a Sansão José Loureiro e de Doutores honoris causa a Paolo Grossi e a António Manuel Hespanha.

Apostamos alto na inclusão e optamos por discutir a política: não nos calamos quando, em 29 de abril de 2015, houve um grande massacre aos professores na Praça Nossa Senhora de Salete. Fizemos, junto com Vera e com os amigos do NPJ, um dos maiores eventos que o Teatro da Reitoria já viu - o julgamento simbólico dos atos lá ocorridos. Com a participação de eminentes juristas daqui e de fora, representantes das entidades atingidas e do Estado do Paraná, nós verdadeiramente balançamos a Universidade naquele início de maio e, com o auxílio da TV UFPR que transmitiu o evento, obtivemos ampla repercussão nacional e até internacional. Foi nesse período em que aqui foi discutida a implementada no ano de 2015 a turma do Pronera, que hoje acolhemos com toda a alegria e envolvimento.

Nós nos abrimos com força e de maneira decisiva para a Universidade: cercas foram derrubadas e pontes foram construídas. Tenho orgulho de dizer que meu primeiro ato de gestão, em 2008, foi o de abrir as portas, no primeiro e no segundo andar do prédio (e que antes eram 
permanentemente fechadas), que nos separavam da ala da psicologia. Esse ato singelo, mas simbólico, que permitiu a circulação de gente nova no miolo desse prédio, foi o que buscamos fazer também com o restante da UFPR: desde 2008 nós participamos, debatemos e contribuímos com todas as questões da nossa comunidade universitária, naquilo que pudemos. Discutimos orçamento, discutimos vagas docentes, discutimos hospitais universitários. Recebemos do Magnífico Reitor, com gosto e com muito espírito institucional, os relatos dos processos mais espinhosos dos últimos anos nos conselhos superiores. Ao mesmo tempo, por participarmos ativamente da vida institucional da Universidade, soubemos aproveitar os editais disponíveis na nossa instituição (sobretudo o FDA Fundo de Desenvolvimento Acadêmico) para compensar o curto cobertor do nosso orçamento setorial: pudemos investir nesses anos pesadamente em nossa biblioteca, em equipamentos para nossas salas de aula, para projetos da pós-graduação, etc.

Fizemos uma gestão de entendimento, de diálogo, em que os conflitos pudessem ser colocados na mesa, discutidos republicanamente e deliberados livremente. Buscamos reforçar o orgulho do pertencimento a esta Casa e sedimentar o sentimento de solidariedade. Porém, em algumas poucas situações, quando foi necessário manter íntegra a racionalidade pública da instituição e demonstrar que ninguém, absolutamente ninguém, está acima dos interesses institucionais, não nos furtamos aos enfrentamentos. E foram feitos na defesa da observância das normas que regulam o funcionamento regular do nosso curso, para manter critérios impessoais e públicos no credenciamento no programa de pós-graduação ou para manter a higidez absoluta nos nossos concursos públicos. Em quaisquer dos casos houve incompreensões, houve cicatrizes, mas vencemos todos os enfrentamentos, inclusive quando foram judicializados. Mas a verdadeira vencedora foi a nossa instituição: estou absolutamente convicto que hoje, ao contrário de ontem, é muito mais difícil a quem quer que seja, independentemente de onde se fale e como se fale, suplantar a lógica institucional impessoal e republicana que agora prevalece dentro desse curso de Direito.

Todavia, creio que o mais visível e plausível seja o crescimento de índices que nenhum critério oficial (seja Inep ou Capes) é capaz de medir oficialmente, mas que aqui hoje todos nós sentimos com força (sobretudo os que viveram tempos diferentes destes): o entendimento, a cortesia, o espírito institucional, a solidariedade, a alegria de subir essas escadarias e atravessar essas colunas, o orgulho de estar aqui e pertencer a essa comunidade.

Mas todos esses atos de gestão, absolutamente todos, não teriam sido levados a cabo se não tivesse existido aquilo que há de mais importante: o trabalho conjunto, coletivo e solidário. Reunir pessoas comprometidas e competentes e poder caminhar junto é, em verdade, aquilo que tornou e torna possível levar essa grande comunidade adiante. Por essa razão que não há como concluir sem 
fazer alguns registros de agradecimento.

E como revelar ingratidão é, a meu ver, um dos defeitos mais deploráveis, preciso, sim, agradecer à Administração Central da UFPR. Quando assumi a Direção, os professores Zaki e Mulinari, então Diretores de Setor, eram candidatos à sua primeira gestão. E desde que eles assumiram em fins de dezembro de 2008 eu estou lá, acompanhando tudo. E devo reconhecer neles interlocutores que sempre foram cordiais, atenciosos e presentes no Setor de Ciências Jurídicas. Não precisamos ter concordado em tudo nesse período e nem andado junto em cada decisão para que eu deva reconhecer aqui, publicamente - como aliás sempre o faço quando estão ambos, ou um ou outro -, que a Faculdade de Direito, até onde minha memória alcança, nunca teve os gestores da Universidade tão presentes. Certamente que não fomos uma unidade que trouxe grandes crises ou problemas para nossa UFPR nesse período, mas de qualquer modo, com relação a nós, devo deixar registrado publicamente como as suas gestões, professor Zaki, professor Mulinari, para nós foram tranquilas e atenderam nossa comunidade no que lhes foi possível. Por isso, o meu muito obrigado e o agradecimento de toda a comunidade setorial.

Mas devo também agradecer àqueles que caminharam junto comigo aqui, para dentro dessas colunas. Mas aqui no curso, a lista seria imensa, pois em alguma medida e em algum momento, quase metade da nossa comunidade em algum momento já me estendeu a mão, trabalhou e se envolveu de algum modo e foi solidário nessa caminhada: na pesquisa, na extensão, nas monografias, na solidariedade que tive, tanta, nos departamentos, nos vários coordenadores (e vices) de curso, nas coordenações (e vices) da pós-graduação, nos servidores comprometidos da graduação e da pósgraduação, no pessoal da informática, do financeiro, na Dona Regina, nas várias gerações de estudantes, entre tantos outros. Registro aqui então um agradecimento aos professores que, em algum momento, maior ou menor, caminharam ou contribuíram na administração do setor, aos servidores técnico-administrativos que sempre estiveram solidários e aos estudantes de várias gerações. Quero registrar um agradecimento sentido, in memoriam, a Alcides Munhoz da Cunha, que, lado a lado, sempre e sempre esteve nos apoiando e incentivando.

Então que me seja permitido fazer somente alguns registros que considero absolutamente necessários: por primeiro, à servidora Jane Kiatkoski - que, como tenho dito, tem se comportado ao longo desses anos como uma das colunas desse prédio. Mas mais do que isso, com seu imenso coração, tem sido solidária, carinhosa, leal comigo desde que eu a trouxe para a secretaria da Direção. Em segundo lugar, ao Luís Fernando Lopes Pereira, que também caminhou junto sempre, seja na coordenação de curso e depois na coordenação do programa de pós-graduação. Em terceiro lugar, à querida amiga Maria Cândida Kroetz, que também se entregou de corpo e alma às lides dessa 
Faculdade, com comprometimento e grande solidariedade.

E por último - mas não menos importante - à querida Vera Karam de Chueiri. Vera para mim, nesse período e até um ano atrás, não foi somente uma vice-diretora; foi também alguém que construiu junto, que com seu jeito doce e manso sabia jogar a razão onde era necessário, sabia ponderar nas situações difíceis. Vera tem uma sapiência única, que fez dela, sem dúvida alguma, a grande corresponsável por qualquer ato que possa ter sido considerado um avanço nesses anos nessa Faculdade.

E se é assim, e se passado e presente têm de fato essa relação inextricável, se é verdade, como diz Walter Benjamin, que "não somos tocados por um sopro de ar que envolveu nossos antepassados? Não existem, nas vozes que agora damos ouvidos, ecos de vozes que emudeceram? [...] Se assim é, então existe um encontro secreto marcados entre as gerações precedentes e a nossa"3; se é verdade, enfim, como diz Adauto Novaes, que "Ver é rever e prever"4, então não há qualquer dúvida que a partir de agora essa Faculdade está sendo entregue para as melhores mãos possíveis - as mãos de Vera Karam de Chueiri. Vera tem os títulos acadêmicos que a credenciam: depois de fazer seu doutorado na New School de Nova York, de ter estudado na Alemanha, de ter sido professora visitante em Portugal, acaba de retornar de um período de um ano de pós-doutorado em Yale, New Haven. Vera é internacional, que é uma das coisas mais importantes para um gestor hoje. E Vera, para além dos títulos (que por vezes podem ser somente credenciais vazias), é uma grande intelectual, à altura dos destinos dessa Casa e do lugar que o futuro está a reservar para ela. E Vera tem sentido republicano, Vera vê com precisão os desafios do futuro dessa Casa. E Vera tem a legitimidade, que conquistou, por méritos próprios, no meio de um ambiente que em muitos momentos também lhe foi hostil. Vera é mulher - e isso agora não é de pouca monta, considerando que nos quase 104 anos de história dessa Casa nós jamais tivemos uma diretora, certamente por ranços que devem cada vez mais ficar no passado; e ranço que, nesse momento, vai se desfazer, pois agora nossa Casa será comandada por uma diretora e por uma vice-diretora. Aqui, de novo para ficarmos com Walter Benjamin, é o momento em que estamos mandando “pelos ares o continuum da história"5, é o momento em que começamos a "escovar a história a contrapelo"6.

E Vera será uma grande Diretora. O agridoce desse momento só se torna mais doce do que agrume pela alegria, Vera, de te passar a partir de agora o comando da nossa Casa.

\footnotetext{
${ }^{3}$ BENJAMIN, Walter. Obras escolhidas - magia e técnica, arte e política: ensaios sobre literatura e história da cultura. 8. ed. São Paulo: Brasiliense, 2012. p. 242.

${ }^{4}$ NOVAES, Adauto (Org). O futuro não é mais o que era. São Paulo: Edições Sesc, 2013. p. 19.

${ }^{5}$ BENJAMIN, Walter. Obras escolhidas - magia e técnica, arte e política: ensaios sobre literatura e história da cultura.

8. ed. São Paulo: Brasiliense, 2012. p. 250.

${ }^{6}$ Ibid., p. 245.
} 
Agradeço à minha família: aos meus filhos que cresceram, desde muito pequenos, vendo o pai somente envolvido com as lidas da Direção do Setor; mas também e sobretudo à Angela, hoje professora da Casa, não só pela solidariedade absoluta, mas por ter sido, ela mesma, em tantos momentos, uma verdadeira vítima pelo fato de eu ter ocupado a Direção desta Casa. Essa solidariedade, nos bons e maus momentos, me faz lembrar de um haicai do Paulo Leminski:

Das coisas que fiz a metro

Todos saberão

Quantos quilômetros são

Aqueles em centímetros

Sentimentos mínimos

Ímpetos infinitos, não?

Pois a Angela sabe.

E já que falei de tempo e falei de memória, e já que tenho esse sentimento agridoce, que é de deixar algo e se abrir para o novo, encerro com um poema justamente chamado "Memória"8, de Drummond:
Amar o perdido
deixa confundido
este coração.
Nada pode o olvido
contra o sem sentido
apelo do Não.
As coisas tangíveis
tornam-se insensíveis
à palma da mão.

${ }^{7}$ LEMINSKI, Paulo. Toda Poesia. São Paulo: Companhia das Letras, 2013.

${ }^{8}$ ANDRADE, Carlos Drummond de. Antologia poética. São Paulo: Companhia das Letras, 2012. p. 175. 
MEMÓRIA E INSTITUIÇÃO: A FACULDADE DE DIREITO DA UFPR ENTRE 2008 E 2016

Mas as coisas findas,

muito mais que lindas,

essas ficarão.

Muito obrigado. 